\title{
Urban Residents' Evaluation of Domestic Recreation Service Quality in China
}

\author{
Yuanhao Qin, Wushuang Fan \\ College of Economics and Management, Southwest University, Chongqing, China \\ Email: 349302237@qq.com
}

Received 8 October 2014; revised 12 November 2014; accepted 25 November 2014

Copyright (C) 2014 by authors and Scientific Research Publishing Inc.

This work is licensed under the Creative Commons Attribution International License (CC BY).

http://creativecommons.org/licenses/by/4.0/

(c) (i) Open Access

\begin{abstract}
Service quality in tourism is the most significant key factor that significantly affects tourist satisfaction and tourist consumption behavior. And as one of the six main factors of travel, tourism recreation affects a lot to tourists' perception. Consulting the basic datum in The Sampling Survey Datum of Chinese domestic tourism (1998-2007), The Sampling Survey Datum of Chinese tourism (2008-2010) and using the methods of quantitative and qualitative analysis, the writer try to analyze tourists' perception and evaluation with domestic tourism recreation. Then the author found that tourists' evaluation growth year by year which is effected by a lot of factors such as occupations of tourists, family incomes and so on. At the end of this article, it provides a reference basis which will further improve the quality of Chinese tourism recreation services.
\end{abstract}

\section{Keywords}

Recreation Service, Quality Evaluation, Quality Improvement

\section{Introduction}

Along with the recent rapid development in tourism, the tourism recreation service is more and more valued; people are increasingly more willing to spend money to enjoy recreation services in the process of tourism. And tourists' perception of recreation service quality functions equivalently to recreational consumption. By means of quantitative determination and qualitative research, according to the basic datum in The Sampling Survey of Chinese domestic tourism (1998-2007) and The Sampling Survey Datum of Chinese tourism (2008-2010), this paper indicates the changing trend of the urban tourists' recreation quality evaluation and probes into the influencing factors of the quality evaluation of domestic recreation service among urban tourists, in order to provide reference basis for the further improvement of Chinese recreation service quality. 


\section{Literature's Review}

Since 1988, recreation has been officially incorporated into the tourism industry as a pivotal factor in China. However, because of a late start, development lagging, lacking of literature, the development of tourism industries still have some gaps between China and other Western developed countries, Deng Zhongde thought China recreation industry has plenty of shortcomings such as an absence of striking characters, repeated construction, comprehensive not strong and difficulty of developing repeated customers. Despite this, this industry will burgeon with very strong development momentum and an extensive perspective. Via literature research method and questionnaire survey, Ma Zheng probed into the customer satisfaction of recreation fitness industry characteristics. Gao Zhengya interpreted the "Tourist entertainment infrastructure management and service standards”, and put forward some reference opinions of the implementation. In the early 1980s, C. Gronröos, a Finnish scholar, and A. Parasuraman, an American scholar, as the representatives of the foreign scholars, carried out an intensive study about service quality perception. Even so, there still lack of research results relating to recreation service quality perception. With the rapid development of China's recreation industry, a piece of research to this problem has great theoretical significance [1]-[7].

\section{Research Method}

\subsection{Sources and Pre-Process of Datum}

The Basic datum of this study originates from The Sampling Survey Datum of Chinese domestic tourism (19982007), The Sampling Survey Datum of Chinese tourism (2008-2010) and researchers’ investigation. Firstly, not until those tourists who never got involved into any recreation service are eliminated from the whole number of tourists do the authors re-calculate the percentage of urban tourists who participate in evaluation of tourism service quality to ensure the accuracy of the analysis. Secondly, "very good”, "good”, "mediocre”, "tolerable” and "bad”, and those every evaluation grades of tourism service quality are converted into "5 points”, “4 points”, “3 points", "2 points" and "1 point”. Lastly, all information of concerned tourists is re-inputted by the software SPSS according to the difference of their demographics so as to analyze their perceived differences of recreation service quality.

\subsection{Analysis Methods of Datum}

The descriptive statistical method is applied to the study of the size of populations involved in different evaluation grades of tourist quality service and the study of inter-annual variation law of recreation service quality evaluation. Mean comparison is used to probe into the overall standard and change trend of its quality evaluation and its difference in the aspect of demographics. Correlation analysis is used to explore the impact of tourism industry environment on evaluation of recreation service quality.

\section{Research Results}

\subsection{The Overall Quality Evaluation of Recreation Service of Urban Tourists}

Given the tourists’ proportion of different service quality evaluation grades, it shows a high acceptance degree and an accumulating approval year after year of tourism service quality. From 1998 to 2010, the ratio of urban tourists who admit favorable (very good/good) or acceptable (mediocre/tolerable) evaluation for recreation service quality has exceeded 99\%. Especially after 2000, for the first time more than 50\% urban tourists admit that recreation service is very good, and the ratio of this evaluation increased year by year and eventually stay in $55 \%$. The ratio of the tourists who regard recreation service quality as "bad" (negative evaluation) has a continuous downward trend from 2.4\% in 1997 to $0.3 \%$ in 2010 (see Figure 1). All these figure shows us that with a steady growth of recreation industry, continual perfection of recreation infrastructure and constant improvement of the staff quality, there is no doubt that Chinese recreation service quality has been continually improved and accepted and praised by more and more tourists (Table 1 ).

\subsection{The Comparison of Evaluation among Overall Tourism Service Quality and Tourism Elements' Service Quality}

Through the statistical analysis of urban tourists' acceptance of tourism overall and elements of tourist service 


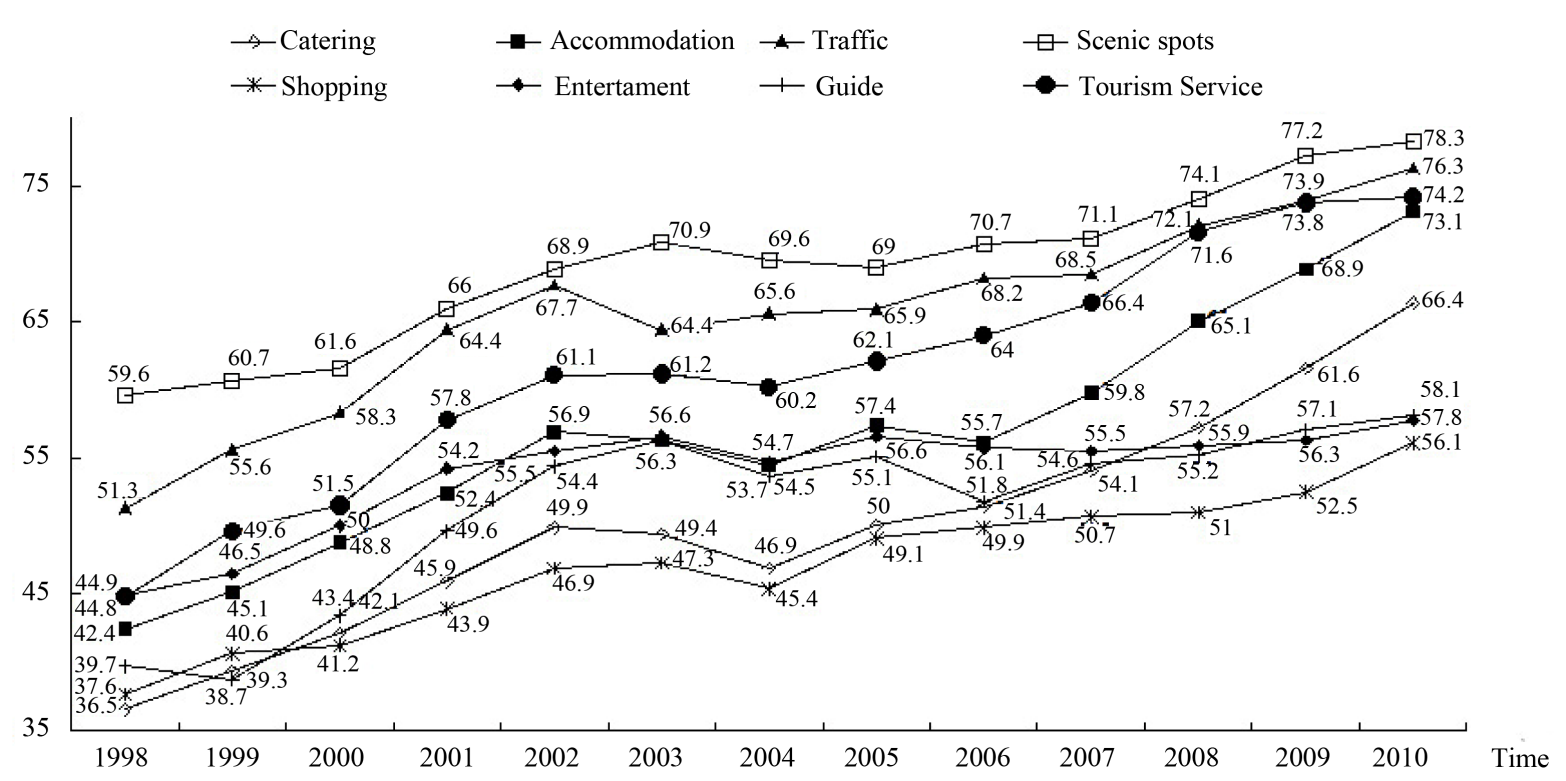

Figure 1. Change trend of urban tourists' quality evaluation of tourism service.

Table 1. Urban tourists’ quality evaluation of recreation service.

\begin{tabular}{cccccccccccccc}
\hline Time & 1998 & 1999 & 2000 & 2001 & 2002 & 2003 & 2004 & 2005 & 2006 & 2007 & 2008 & 2009 & 2010 \\
\hline Respondents & 4557 & 4708 & 5692 & 5603 & 6739 & 5337 & 6623 & 7528 & 9152 & 9991 & 12131 & 13599 & 13748 \\
Favorable (\%) & 44.9 & 46.5 & 50.0 & 54.2 & 55.5 & 56.5 & 54.7 & 56.6 & 55.7 & 55.5 & 55.9 & 56.3 & 57.8 \\
Acceptable (\%) & 52.7 & 51.9 & 48.3 & 44.0 & 43.9 & 42.1 & 44.4 & 43.1 & 43.7 & 44.2 & 43.7 & 43.4 & 41.9 \\
Negative (\%) & 2.4 & 1.6 & 1.4 & 1.0 & 0.6 & 1.4 & 0.9 & 0.4 & 0.6 & 0.4 & 0.4 & 0.3 & 0.3 \\
\hline
\end{tabular}

(such as catering service, accommodation service, traffic, service in scenic spots, tour guide service, shopping service and entertainment service) quality, we discover (see Figure 1): 1) The ratio trends of tourists' acceptance of tourism service quality and tourism elements' service quality are almost the same. However, compared with the acceptance ratio of overall tourism service quality, the acceptance ratio of entertainment service is much lower except 1998; 2) Before 2001, the proportion of service quality acceptance ratio of recreation ranked third amongst other tourism service elements, yet it dropped to the second-lowest in 2010. The ratios of tourists' favorable evaluation of overall tourism service and in aspects of catering, service accommodation service, traffic service, scenic spot service, tour guide service, shopping service and entertainment service respectively increased by 29.45\%, 29.86\%, 30.69\%, 25.08\%, 18.69\%, 18.39\%, 18.48\% and 12.9\%, while the ratios of tourists' favorable evaluation of recreation has the smallest increase and the slowest growth rate. All in all, this shows that recreation service quality is low in overall tourism service quality. The recreation industry development lags behind the whole tourism industry. Therefore, recreation industry standard and system remains to be perfect, and the professional quality of employees also needs to be further improved.

\subsection{The Factors Affecting Urban Tourists' Evaluation of Recreation Service Quality}

\subsubsection{The Individual Characteristics of Urban Tourists}

Due to specific individual characteristics such as the gender, age, educational background, monthly family income, occupations and so on, as well as apparently different choice of tourism service project and tourism activities, dissimilar awareness of tourism service on tour, therefore, tourists' perception and evaluation of the recreation service quality may be different.

1) Gender

The results of mean comparison indicate that gender have no obvious influence on the urban tourists' service quality evaluation. From Table 2, the average ratio of recreation service quality evaluation given by urban 
Table 2. Urban tourists’ quality evaluation of recreation service: based on gender.

\begin{tabular}{cccccccccccccc}
\hline & 1998 & 1999 & 2000 & 2001 & 2002 & 2003 & 2004 & 2005 & 2006 & 2007 & 2008 & 2009 & 2010 \\
\hline male & 3.32 & 3.39 & 3.45 & 3.55 & 3.58 & $\underline{\mathbf{3 . 6 0}}$ & 3.53 & 3.59 & 3.58 & 3.58 & 3.61 & 3.60 & 3.63 \\
female & 3.35 & 3.39 & 3.46 & 3.54 & 3.60 & $\underline{\mathbf{3 . 5 7}}$ & 3.55 & 3.60 & 3.58 & 3.56 & 3.60 & 3.61 & 3.62 \\
\hline
\end{tabular}

Illustration: a significant difference between underscored mean values and other bold ones.

tourists with different gender to be similarly stable in most years except 2003. This shows that it doesn't matter if a tourist is male or females, it makes no difference on service quality evaluation (Table 2).

2) Age

By One-Way ANOVA analysis and LSD test, it points out that among urban civilizations, teenager's (under 25 years old) favorable evaluation is much higher than others age group's evaluation, especially the children under 14 give a particularly high evaluation on recreation service. This is due to junior tourists who have less travel experience are easily to be satisfied and easily to be affected by a pleasant entertainment atmosphere. For another, most of scenic spot in china give priority to building amusement parks or constructing some recreation facilities, it is more aligned with adolescents' appetite. Before 2000, the ratio of favorable evaluation given by 25 to 44-year-old tourists is lower than that given by senior tourists over 65-year-old. But since 2001, all the three age groups' favorable evaluation tends to be same. This shows that recreation services whether from hardware or software are paid more attention to cater to a wider age groups of tourists, and begins to realizing the diversification and localization of entertainment (Table 3).

3) Educational

Urban residents due to the difference in the level of education cause differences within the recreation service quality evaluation, this mainly shows in that the evaluation of primary education degree visitors is much higher than the evaluation given by higher or secondary education degree visitors. First of all, primary education degree visitors they are young and their cognitive ability is weak, their needs are easy to satisfy. Secondly, higher or secondary education degree visitors they have lower evaluation because they hold a high expectation, however, domestic quality level and their expectations have a larger gap. After 2003, there are still some gaps among three education level groups, but the gaps are getting smaller and smaller. This shows recreation service quality have improved a lot this year, it not only can meet the needs of the younger tourists but also the older ones (Table 4).

4) Monthly family income

Different monthly income level residents hold different attitude towards the recreation service quality. The favorable ratio of urban tourists whose monthly family income over 5000 RMB or below 1000 RMB keeps evidently lower than that of those whose monthly family income is from 1000 - 4999 RMB, while the favorable proportion of only those whose family income below 1000 RMB is obviously lower than that of tourists with family income is over 1000 RMB. Therefore, according to the relevant survey data, tourists with the largest spending per capita on their tour are those whose monthly family income over $5000 \mathrm{RMB}$; however, in that newly initial stage of domestic tourism, spending more does not means the better purchase of satisfying products or services even though tourist are willing to pay for them. As the domestic tourism fully develops with more and more products and services and multiple choices for tourists, tourism has strengthened its capacity to meet the needs of consumers who can obtain better products and services only if they are affordable. After 2003, urban tourists in possession of a monthly family income under 1000 RMB spent the least on average on their tour. Due to their limited expenditure, hence, what they can access and afford are often those relatively low-quality goods and services, and as a consequence of that those tourists may show a correspondingly low-ability of perception. With China's accession to the World Trade Organization (WTO) and more recreation related law and regulations introduced, the recreation industry is developing and maturing. Products and services are more and more plentiful, more options are available to high income groups, there is the growth of industry standards and the improvement of the overall quality increases its ability to meet the demand of tourists (Table 5).

5) Occupation

Different occupations of tourists will impact upon the perception of recreation service quality difference. Students and retirees give a higher evaluation of the service they received, and the favorable ratio variation trends of students and retirees are more stable than others. Students' evaluation of recreation service ranks the best among the residents of the other professions, in terms of that student tourists have less economic pressure so they are free to choose entertainment activities according to their own preference. Many new entertainment 
Table 3. Urban tourists’ quality evaluation of recreation service: based on ages.

\begin{tabular}{cccccccccccccc}
\hline & 1998 & 1999 & 2000 & 2001 & 2002 & 2003 & 2004 & 2005 & 2006 & 2007 & 2008 & 2009 & 2010 \\
\hline$<14$ & $\mathbf{3 . 6 2}$ & $\mathbf{3 . 6 0}$ & $\mathbf{3 . 6 2}$ & $\mathbf{3 . 7 4}$ & $\mathbf{3 . 7 4}$ & $\mathbf{3 . 6 9}$ & $\mathbf{3 . 7 2}$ & $\mathbf{3 . 7 0}$ & $\mathbf{3 . 7 1}$ & $\mathbf{3 . 7 1}$ & $\mathbf{3 . 7 6}$ & $\mathbf{3 . 7 7}$ & $\mathbf{3 . 7 7}$ \\
$15-24$ & $\underline{\mathbf{3 . 4 5}}$ & $\mathbf{3 . 5 1}$ & $\mathbf{3 . 5 8}$ & $\underline{3.57}$ & $\underline{3.60}$ & 3.63 & $\underline{3.56}$ & 3.69 & 3.69 & $\underline{3.60}$ & $\mathbf{3 . 7 0}$ & $\mathbf{3 . 7 1}$ & 3.71 \\
$25-44$ & $\underline{\underline{3.26}}$ & $\underline{3.36}$ & $\underline{3.40}$ & $\underline{\mathbf{3 . 4 8}}$ & $\underline{3.58}$ & $\underline{3.55}$ & $\underline{3.52}$ & $\underline{3.56}$ & $\underline{3.57}$ & $\underline{3.55}$ & $\underline{3.63}$ & $\underline{3.65}$ & $\underline{3.65}$ \\
$45-64$ & $\underline{3.31}$ & $\underline{3.33}$ & $\underline{3.41}$ & $\underline{3.54}$ & $\underline{3.53}$ & $\underline{3.59}$ & $\underline{3.53}$ & $\underline{3.58}$ & $\underline{3.54}$ & $\underline{3.55}$ & $\underline{3.64}$ & $\underline{2.62}$ & $\underline{3.64}$ \\
$>65$ & $\underline{\mathbf{3 . 4 4}}$ & $\underline{3.34}$ & $\mathbf{3 . 5 6}$ & $\underline{3.57}$ & $\underline{3.54}$ & $\underline{3.56}$ & $\underline{3.54}$ & 3.59 & $\underline{3.55}$ & $\underline{3.51}$ & $\underline{3.60}$ & 3.66 & $\underline{3.61}$ \\
\hline
\end{tabular}

Illustration: a significant difference between underscored mean values and other bold ones.

Table 4. Urban tourists' quality evaluation of recreation service: based on educational.

\begin{tabular}{cccccccccccccc}
\hline & 1998 & 1999 & 2000 & 2001 & 2002 & 2003 & 2004 & 2005 & 2006 & 2007 & 2008 & 2009 & 2010 \\
\hline Primary & $\mathbf{3 . 4 3}$ & $\mathbf{3 . 4 3}$ & $\mathbf{3 . 5 2}$ & $\mathbf{3 . 5 8}$ & $\mathbf{3 . 6 3}$ & $\mathbf{3 . 4 3}$ & $\mathbf{3 . 6 0}$ & $\mathbf{3 . 6 8}$ & $\mathbf{3 . 6 5}$ & 3.59 & $\mathbf{3 . 6 7}$ & 3.71 & $\mathbf{3 . 7 3}$ \\
Secondary & 3.33 & $\underline{3.38}$ & $\underline{3.39}$ & 3.54 & $\underline{3.56}$ & $\underline{3.58}$ & $\underline{3.52}$ & $\underline{3.57}$ & $\underline{3.57}$ & 3.55 & $\underline{3.61}$ & 3.72 & $\mathbf{3 . 7 1}$ \\
Higher & $\underline{3.30}$ & $\underline{\mathbf{3 . 4 6}}$ & $\underline{\mathbf{3 . 4 6}}$ & $\underline{3.52}$ & $\underline{\mathbf{3 . 9 5}}$ & $\underline{3.55}$ & $\underline{3.48}$ & $\underline{3.60}$ & $\underline{3.58}$ & 3.57 & $\underline{3.63}$ & 3.72 & $\underline{3.59}$ \\
\hline
\end{tabular}

Illustration: a significant difference between underscored mean values and other bold ones.

Table 5. Mean comparison of urban tourists' quality evaluation of recreation service.

\begin{tabular}{|c|c|c|c|c|c|c|c|c|c|c|c|c|c|c|}
\hline & & \multicolumn{2}{|c|}{1998} & \multicolumn{2}{|c|}{1999} & \multicolumn{2}{|c|}{2000} & \multicolumn{2}{|c|}{2001} & \multicolumn{2}{|c|}{2002} & \multicolumn{3}{|c|}{2003} \\
\hline \multirow{6}{*}{$\begin{array}{l}\text { Family } \\
\text { Monthly } \\
\text { Income } \\
\text { (RMB) }\end{array}$} & $<1000 \mathrm{RMB}$ & $\underline{3.21}$ & & $\underline{3.30}$ & 3.30 & 3.27 & $\underline{3.27}$ & $\underline{3.41}$ & & $\underline{3.49}$ & & & 3.62 & \\
\hline & 1000 - 1999 RMB & 3.36 & $\underline{3.36}$ & 3.40 & 3.40 & 3.49 & 3.49 & 3.59 & 3.59 & 3.60 & 3.60 & & 3.58 & \\
\hline & 2000 - 2999 RMB & 3.42 & 3.42 & 3.49 & $\underline{3.49}$ & 3.52 & 3.52 & 3.64 & 3.64 & 3.65 & & & 3.60 & \\
\hline & 3000 - 3999 RMB & 3.46 & 3.46 & 3.43 & & 3.53 & 3.53 & 3.52 & 3.52 & 3.68 & $\underline{3.68}$ & & 3.63 & \\
\hline & 4000 - 4999 RMB & $\underline{3.32}$ & & 3.36 & & 3.58 & 3.58 & 3.54 & 3.54 & 3.48 & 3.48 & & $\underline{3.49}$ & \\
\hline & $>5000 \mathrm{RMB}$ & 3.37 & & 3.29 & 3.29 & $\underline{3.12}$ & & 3.26 & $\underline{3.26}$ & $\underline{3.42}$ & & & $\underline{3.48}$ & \\
\hline \multirow{8}{*}{ Occupation } & Students & $\underline{3.56}$ & & \multicolumn{2}{|c|}{$\underline{3.56}$} & $\underline{3.61}$ & & \multicolumn{2}{|c|}{3.68} & \multicolumn{2}{|c|}{$\underline{3.68}$} & \multicolumn{3}{|c|}{$\underline{3.65}$} \\
\hline & Retiree & 3.41 & 3.41 & \multicolumn{2}{|c|}{3.41} & 3.50 & $\underline{3.50}$ & \multicolumn{2}{|c|}{3.56} & \multicolumn{2}{|c|}{3.56} & \multicolumn{3}{|c|}{3.58} \\
\hline & Soldier & 3.06 & & \multicolumn{2}{|c|}{3.44} & 3.46 & & \multicolumn{2}{|c|}{$\underline{3.28}$} & \multicolumn{2}{|c|}{3.70} & \multicolumn{3}{|c|}{3.59} \\
\hline & Worker & 3.31 & & \multicolumn{2}{|c|}{3.36} & 3.40 & 3.40 & \multicolumn{2}{|c|}{3.49} & \multicolumn{2}{|c|}{3.59} & \multicolumn{3}{|c|}{3.58} \\
\hline & Trade servicer & 3.28 & & \multicolumn{2}{|c|}{3.32} & 3.43 & & \multicolumn{2}{|c|}{3.51} & \multicolumn{2}{|c|}{3.57} & & 3.63 & \\
\hline & Management & 3.26 & $\underline{3.26}$ & & 38 & 3.46 & & & & & & & 3.55 & \\
\hline & Civil servant & 3.21 & $\underline{3.21}$ & & 31 & 3.34 & 3.34 & & & & & & 3.59 & \\
\hline & & & 04 & & 05 & & & & & & & 2009 & & \\
\hline & $<1000 \mathrm{RMB}$ & & 57 & & 58 & & & & & & & $\underline{3.58}$ & $\underline{3.58}$ & 3.67 \\
\hline & 1000 - 1999 RMB & & 58 & & 61 & & & & & & & $\underline{3.60}$ & & $\underline{3.65}$ \\
\hline Monthly & 2000 - 2999 RMB & & 60 & & 60 & 3. & & & & & & 3.68 & 3.68 & 3.68 \\
\hline $\begin{array}{l}\text { Income } \\
\text { (RMB) }\end{array}$ & 3000 - 3999 RMB & & 59 & & 64 & & & & & & & 3.67 & 3.67 & 3.69 \\
\hline & 4000 - 4999 RMB & & 41 & & 63 & & & & & & & $\underline{3.63}$ & & 3.71 \\
\hline & >5000 RMB & & 31 & & 48 & 3. & & & & & & 3.72 & & 3.73 \\
\hline & Students & $\underline{3.64}$ & & $\underline{3.68}$ & & $\underline{3.71}$ & & $\underline{3.66}$ & & $\underline{3.69}$ & $\underline{3.71}$ & $\underline{3.73}$ & & \\
\hline & Retiree & 3.58 & & 3.59 & & 3.57 & & 3.57 & 3.57 & 3.57 & 3.59 & 3.61 & & \\
\hline Occunation & Worker & 3.49 & & 3.60 & & 3.54 & 3.54 & 3.50 & $\underline{3.50}$ & 3.56 & 3.60 & 3.51 & & \\
\hline uccupauon & Trade servicer & 3.58 & & 3.60 & & 3.58 & & 3.58 & 3.58 & 3.58 & 3.61 & 3.59 & & \\
\hline & Technical & 3.43 & 3.43 & 3.60 & & 3.61 & $\underline{3.61}$ & 3.56 & & 3.57 & 3.61 & 3.62 & & \\
\hline & Management & 3.50 & & 3.57 & & 3.57 & & 3.56 & & 3.59 & 3.57 & 3.60 & & \\
\hline & Civil servant & 3.48 & & 3.62 & $\underline{3.62}$ & 3.52 & 3.52 & 3.59 & 3.59 & 3.55 & 3.58 & 3.64 & & \\
\hline
\end{tabular}

Illustration: a significant difference between underscored mean values and other bold ones. 
projects have been introduced and developed a number of pieces of advanced equipment. As young people, students are able as one of young groups, able to accept fresh things, can easily experience the fun of the recreation. For another, retired people have more disposable income than most other travelers and more time to spend it, they are satisfied with the ordinary recreation projects such as cultural and artistic performances or board games.

Compared with residents of other professions, soldiers and workers hold lower evaluation of recreation service due to the limitations of their time and income. It's difficult for them to obtain a higher experience of recreation (Table 5).

6) Travel motivation

Out of different motivation and ways of traveling, tourists will encounter different tourism employees and service facilities when they get participated into some tourism service project.

Residents who travel for education, science and technology give a pretty high evaluation of recreation service quality. Otherwise, people who travel for business or official meeting have a few options to experience recreation service quality by reason of a lot of travel limitations. With the continuous development of our economy, and the improvement of star hotels and commercial hotels, the evaluation of residents travel for business or official meeting is getting higher and higher. As to motivation for traveling, tourists who attempt to visit relatives and friends or act on religious pilgrimage tend to give less favorable evaluations than those who travel out of landscape sightseeing, health spa, official business meeting, exchanges in culture, education and science and technology, etc. Besides, tourists motivated by commercial purposes have been significantly less than those by the other aforementioned purposes since 2000 (see Table 6), which indicates that motivation of traveling plays a certain role in their evaluation of tourism service quality.

Table 6. Urban tourists’ quality evaluation of recreation service: based on travel motivation.

\begin{tabular}{|c|c|c|c|c|c|c|c|c|c|c|c|c|c|}
\hline & \multicolumn{3}{|c|}{1998} & \multicolumn{4}{|c|}{1999} & \multicolumn{3}{|c|}{2000} & \multicolumn{3}{|c|}{2001} \\
\hline $\begin{array}{l}\text { Exchanges in culture, } \\
\text { education, science \& } \\
\text { technology }\end{array}$ & $\underline{3.78}$ & & & 3.27 & 3.27 & & & 3.60 & & & & 3.41 & \\
\hline religion & 3.28 & 3.28 & 3.28 & 3.56 & & & $\underline{3.56}$ & 3.17 & 3.17 & 3.17 & 3.17 & & \\
\hline Healing \& vacation & 3.37 & 3.37 & & 3.50 & $\underline{3.50}$ & & & 3.55 & 3.55 & & & $\underline{3.63}$ & $\underline{3.63}$ \\
\hline meeting & 3.21 & 3.21 & 3.21 & 3.28 & 3.28 & $\underline{3.28}$ & 3.28 & 3.41 & 3.41 & $\underline{3.41}$ & & 3.48 & 3.48 \\
\hline business & 3.02 & $\underline{3.02}$ & & 3.25 & & 3.25 & 3.25 & 3.26 & 3.26 & & 3.26 & 3.33 & 3.33 \\
\hline Visiting to relatives \& friends & 3.21 & 3.21 & 3.21 & 3.27 & 3.27 & & 3.27 & 3.41 & 3.41 & 3.41 & 3.41 & 3.45 & 3.45 \\
\hline \multirow[t]{2}{*}{ sightseeing } & 3.37 & 3.37 & $\underline{3.37}$ & $\underline{3.47}$ & & & & 3.46 & 3.46 & & $\underline{3.46}$ & $\underline{3.57}$ & \\
\hline & \multicolumn{3}{|c|}{2002} & & \multicolumn{2}{|c|}{2003} & & 2004 & & 2005 & \multicolumn{3}{|c|}{2006} \\
\hline $\begin{array}{l}\text { Exchanges in culture, } \\
\text { education, science \& } \\
\text { technology }\end{array}$ & $\underline{3.63}$ & & & & 3.65 & & 3.44 & 3.44 & & 3.58 & 3.45 & & 3.45 \\
\hline religion & 3.22 & & $\underline{3.22}$ & & 3.46 & & $\underline{3.07}$ & & & 3.57 & 3.41 & & 3.41 \\
\hline Healing \& vacation & 3.61 & 3.61 & 3.61 & 3.61 & 3.60 & & 3.63 & $\underline{3.63}$ & & $\underline{3.64}$ & $\underline{3.67}$ & & \\
\hline meeting & 3.55 & $\underline{3.55}$ & 3.55 & & 3.53 & $\underline{3.53}$ & 3.54 & & & 3.61 & 3.42 & & 3.42 \\
\hline business & 3.24 & 3.24 & & & 3.75 & 3.75 & 3.39 & 3.39 & & 3.44 & 3.34 & & 3.34 \\
\hline Visiting to relatives \& friends & 3.47 & 3.47 & & $\underline{3.47}$ & 3.51 & & 3.44 & 3.44 & $\underline{3.44}$ & 3.54 & 3.45 & & 3.45 \\
\hline \multirow[t]{2}{*}{ sightseeing } & 3.64 & 3.64 & 3.64 & 3.64 & 3.59 & & 3.54 & 3.54 & 3.54 & 3.59 & 3.62 & & $\underline{3.62}$ \\
\hline & & 2007 & & & 2008 & & & & 2009 & & & 2010 & \\
\hline $\begin{array}{l}\text { Exchanges in culture, } \\
\text { education, science \& } \\
\text { technology }\end{array}$ & 3.44 & & 3.44 & & & & & & & & & & \\
\hline religion & 3.21 & & & & & & & & & & & & \\
\hline Healing \& vacation & 3.61 & 3.61 & & 3.65 & & 3.65 & & 3.6 & & 3.64 & & 3.67 & \\
\hline meeting & 3.57 & 3.57 & & 3.56 & & 3.56 & & 3.5 & & 3.55 & & 3.58 & \\
\hline business & 3.58 & & & & & & & & & & & & \\
\hline Visiting to relatives \& friends & 3.46 & 3.46 & & 3.48 & & & & 3.5 & & & & 3.53 & \\
\hline sightseeing & 3.61 & 3.61 & 3.61 & 3.64 & & & & 3.6 & & & & 3.66 & \\
\hline
\end{tabular}

Illustration: a significant difference between underscored mean values and other bold ones. 
7) Ways of traveling

The results of mean comparison indicate that group' tourists are tended to give favorable evaluation of service than individuals tourists before 2000. After 2003 which is our first official year for joining the WTO, the evaluation given by individual tourists have an increasing momentum due to the improvement of a freer travel system. In 2004, both of the ways of traveling reach a basic agreement on their evaluation. This phenomenon indicates the effect of urban tourists' ways of traveling has waned gradually (Table 7).

\subsubsection{Travel Expenditure}

The amount of travel expenditure will determine the quantity and quality of goods and service tourists obtain on tour, while in return this quantity and typically quality will impact tourists' evaluation. From 1997 to 2010, urban tourists' per capita spending on traveling has increased from 599.8 RMB to 831 RMB, and over the same period the mean value of their service quality evaluation has mounted from 3.35 to 3.92. Plus, the result of correlation analysis presents a significant positive correlation between tourists' evaluation and their travel expenditure.

\subsubsection{Constant Optimization of Recreation Industry Elements}

From the mid-1990s, China's tourism industry has developed rapidly with a large scale expansion of accommodation facilities and increasingly greater capacity to meet tourists' needs, recreation industry as well. During 1997-2010, Chinese star-rated tourist hotels increased from 2724 to 13,991. Meanwhile, in order to guarantee the rapid expansion of the tourism scale, related departments have successively issued and implemented a series of national standards, departmental standards and industrial standards to specify the development of tourist industry elements such as recreation, for instance, Quality Standard of Tourist Boats Service (2000), The Division and Assessment of the Tourist Star-rate Hotels (1999; 2002), Tourist Entertainment Infrastructure Management and Service Standards. As the essential factor to influence quality of domestic recreation service and its evaluation, the implementation of all these standards has not only fostered the rapid and sustainable development of recreation industry, but comprehensively optimized the service quality.

\section{Conclusion and Suggestion}

\subsection{Conclusions}

The following conclusions can be drawn from the comprehensive analysis of the urban tourists' quality evaluation of domestic recreation service from 1998 to 2010.

1) The ratio of acceptable evaluation of recreation service quality given by urban tourist increases significantly, and it shows a rising trend year by year.

2) Urban tourists give more and more favorable evaluation year by year regarding recreation service quality, but it is significantly lower than overall tourism service quality and quality of other tourism service elements. The ratios of favorable evaluation rise at a slow pace.

3) According to the two methods-mean comparison and correlation analysis, the project shows urban tourists' evaluation is impacted to some extend by certain individual characteristics. Amongst these, gender affects the level of evaluation slightly, while age and education background have a more obvious effect on it. Families monthly income, occupation and travel purpose have a significant effect on recreation service quality evaluation.

4) The evaluation of recreation service quality will be significantly affected by the sum of the per capita spending on traveling and constant optimization of recreation industry.

\subsection{Suggestion}

1) Further optimization of recreation industry and comprehensive improvement of its service quality.

Table 7. Urban tourists' quality evaluation of recreation service: based on ways of traveling.

\begin{tabular}{llllllllllllll}
\hline & 1998 & 1999 & 2000 & 2001 & 2002 & 2003 & 2004 & 2005 & 2006 & 2007 & 2008 & 2009 & 2010 \\
\hline Groups & 3.37 & 3.40 & 3.46 & $\underline{\mathbf{3 . 4 8}}$ & $\underline{\mathbf{3 . 4 8}}$ & $\underline{\mathbf{3 . 4 5}}$ & 3.62 & 3.50 & 3.58 & 3.58 & 3.69 & 3.73 & 3.82 \\
Individuals & 3.33 & 3.36 & 3.42 & $\underline{\mathbf{3 . 5 6}}$ & $\underline{\mathbf{3 . 6 1}}$ & $\underline{\mathbf{3 . 6 2}}$ & 3.63 & 3.54 & 3.58 & 3.54 & 3.67 & 3.69 & 3.81 \\
\hline
\end{tabular}

Illustration: a significant difference between underscored mean values and other bold ones. 
Recreation industry as a branch of tourism industry started late but rapidly developed with tremendous potential. The process of development brings many problems such as public security issues, fire control problems and entertainment facilities security issues. Further optimization of recreation service quality is the key to accumulation of more favorable evaluation. In our opinion, we should further strengthen and optimize relevant norms and standard of this industry to run recreation service in a well-ordered way, put forward its development rapidly and guarantee its continuous improvement of its quality.

2) Optimization of industry structure, market segments for meeting various levels of demands requires.

In China, the gap between rich and poor have created diverse residents' ages, family monthly income, education backgrounds and so on quite different. It results in a difference for recreation service requirements. Due to the common service quality problems, it is difficult to meet the needs of all levels residents. Hence, in the development of the recreation industry, we should pay more attention to adjust and optimize industrial structure. We should identify that self-guided tour, in-depth tour, and theme tour will be the new demands of the future Chinese outbound travel market. The recreation service quality needs to be upgraded to meet various levels of demands requires.

3) Stepping up the development of our national economy and striving to carry to a new and higher level of national income.

As the national income decides their payment, the higher tourists' income, the better the products and services they consume with more money. Therefore, if we work on a higher level of urban tourists' quality evaluation of domestic recreation service, we should not only improve its service quality, but also step up the development of our national economy. In addition, we should strive to carry to a new and higher level of national income to ensure their greater consumption abilities so that they can access to and afford to those higher-quality goods and services, which will raise the level of their perception of service quality.

\section{References}

[1] Deng, Z.D. (2004) When China Dance to Beat the World Tourism Entertainment Industry. China Tourism Paper, 2004-03-10.

[2] Ma, Z. (2010) Tourists Scenic Spot Service Quality Evaluation Research. Ph.D. Thesis, Northwestern University, Xi'an.

[3] Gao, Z.Y. (2012) The Research of GB/T 26353-2010 “Tourist Entertainment Infrastructure Management and Service Standards”. The Study of China's Standardization, 78-80.

[4] Gronröos, C.A. (1984) Service Quality Model and Its Marketing Implication. European Journal of Marketing, 18, 3644. http://dx.doi.org/10.1108/EUM0000000004784

[5] Parasuraman, A., Zeithaml, V.A. and Berry, L.L. (1985) A Conceptual Model of Service Quality and Its Implications for Future Research. Journal of Marketing, 49, 41-50. http://dx.doi.org/10.2307/1251430

[6] Martin, W.B. (1997) Defining What Service Quality Is for You. 59-63, 52.

[7] Lehtinen, U. and Lehtinen, J.R. (1982) A Study of Quality Dimensions. Service Management Institute, 5, 25-32. 
Scientific Research Publishing (SCIRP) is one of the largest Open Access journal publishers. It is currently publishing more than 200 open access, online, peer-reviewed journals covering a wide range of academic disciplines. SCIRP serves the worldwide academic communities and contributes to the progress and application of science with its publication.

Other selected journals from SCIRP are listed as below. Submit your manuscript to us via either submit@scirp.org or Online Submission Portal.
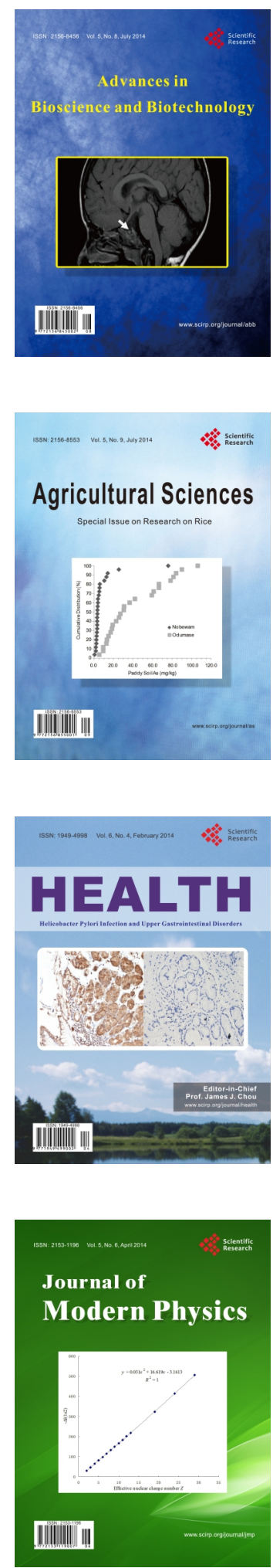
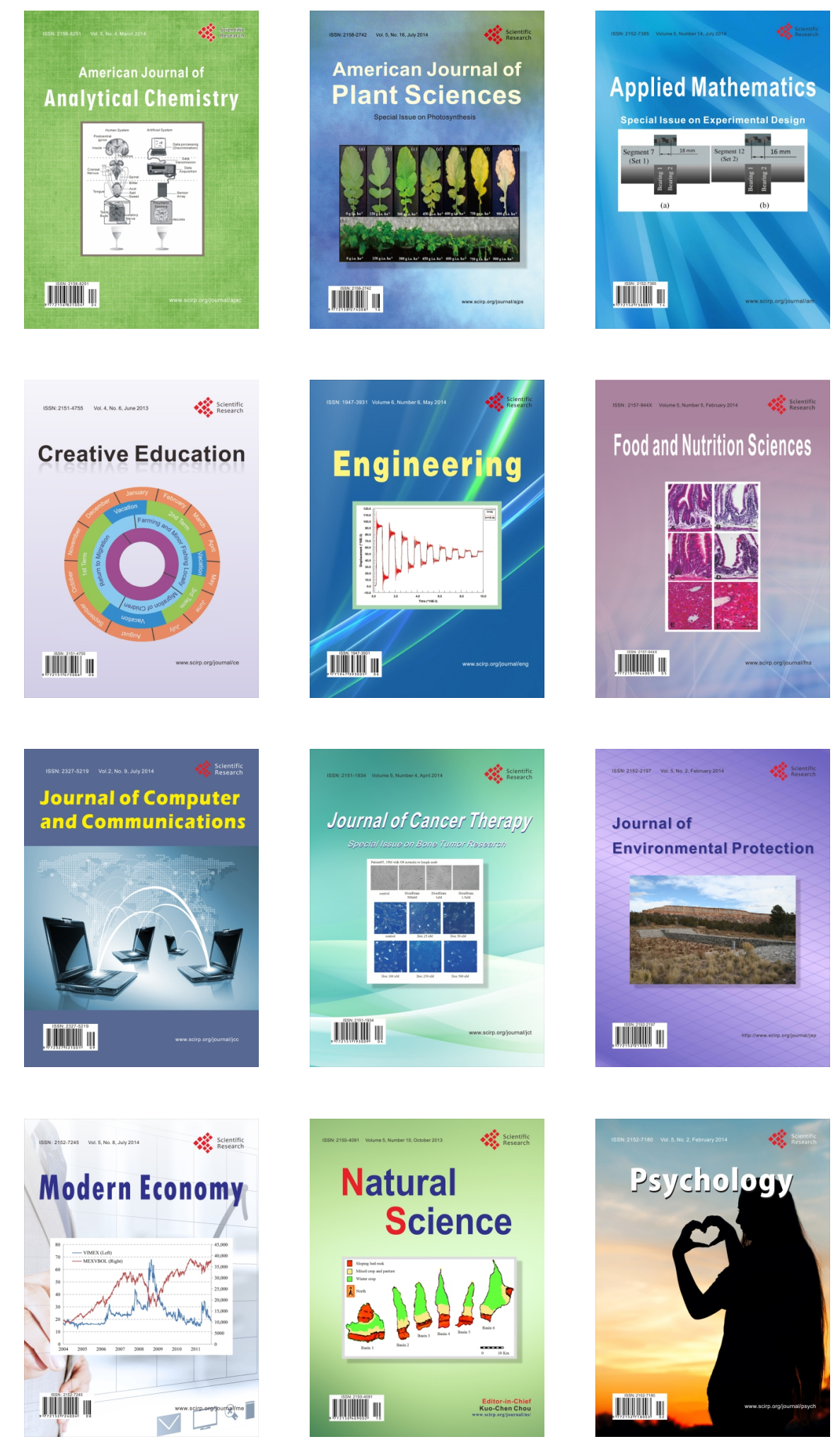